CUBO A Mathematical Journal

Vol.14, $N^{\underline{O}} 01$, (21-27). March 2012

\title{
Remarks on cotype and absolutely summing multilinear operators
}

\author{
A. Thiago Bernardino \\ UFRN/CERES, \\ Centro de Ensino Superior do Seridó, \\ Rua Joaquim Gregório, S/N, 59300-000, Caicó- RN, Brazil, \\ email: thiagobernardino@yahoo.com.br
}

\begin{abstract}
In this short note we present some new results concerning cotype and absolutely summing multilinear operators, extending recent results from different authors.
\end{abstract}

\section{RESUMEN}

En esta nota presentamos nuevos resultados sobre cotipo y suma absoluta de operadores multilineales, extendiendo resultados recientes de diferentes autores.

Keywords and Phrases: Absolutely p-summing multilinear operators, cotype.

2010 AMS Mathematics Subject Classification: 46G25, 47B10. 


\section{Introduction}

In this note the letters $X_{1}, \ldots, X_{n}, X, Y$ will denote Banach spaces over the scalar field $\mathbb{K}=\mathbb{R}$ or $\mathbb{C}$.

From now on the space of all continuous $n$-linear operators from $X_{1} \times \cdots \times X_{n}$ to $Y$ will be denoted by $\mathcal{L}\left(X_{1}, \ldots, X_{n} ; Y\right)$. If $1 \leq s<\infty$, the symbol $s^{*}$ represents the conjugate of $s$. It will be convenient to adopt that $s / \infty=0$ for any $s>0$. For $1 \leq q<\infty$, we denote by $\ell_{\mathrm{q}}^{w}(X)$ the set $\left\{\left(x_{j}\right)_{j=1}^{\infty} \subset X: \sup _{\varphi \in B_{X *}} \sum_{j}\left|\varphi\left(x_{j}\right)\right|^{q}<\infty\right\}$.

If $0<p, q_{1}, \ldots, q_{n}<\infty$ and

$$
\frac{1}{p} \leq \frac{1}{q_{1}}+\cdots+\frac{1}{q_{n}},
$$

a multilinear operator $T \in \mathcal{L}\left(X_{1}, \ldots, X_{n} ; Y\right)$ is absolutely $\left(p ; q_{1}, \ldots, q_{n}\right)$-summing if

$$
\left(T\left(x_{j}^{(1)}, \ldots, x_{j}^{(n)}\right)\right)_{j=1}^{\infty} \in \ell_{p}(Y)
$$

for every $\left(x_{j}^{(k)}\right)_{j=1}^{\infty} \in \ell_{q_{k}}^{w}\left(X_{k}\right), k=1, \ldots, n$. In this case we write $T \in \Pi_{p, q_{1}, \ldots, q_{n}}^{n}\left(X_{1}, \ldots, X_{n} ; Y\right)$. If $\mathrm{q}_{1}=\cdots=\mathrm{q}_{\mathrm{n}}=\mathrm{q}$, we write $\Pi_{\mathrm{p}, \mathrm{q}}^{\mathrm{n}}\left(\mathrm{X}_{1}, \ldots, X_{\mathrm{n}} ; Y\right)$ instead of $\Pi_{\mathrm{p}, \mathrm{q}, \ldots, \mathrm{q}}^{\mathrm{n}}\left(X_{1}, \ldots, X_{n} ; Y\right)$. For details on the linear theory we refer to the excellent monograph [9] and for the multilinear theory we refer to $[1,7,14]$ and references therein.

This paper deals with the connection between cotype and absolutely summing multilinear operators; this line of investigation begins with [4] and was followed by several recent papers (we refer, for example, to $[5,6,8,11,12,13,15,16]$ and for a full panorama we mention [14]). The following result appears in [10, Theorem 3 and Remark 2] and [16, Corollary 4.6] (see also [5, Theorem 3.8 (ii)] for a particular case):

Theorem 1.1 (Inclusion Theorem). Let $\mathrm{X}_{1}, \ldots, \mathrm{X}_{\mathrm{n}}$ be Banach spaces with cotype $\mathrm{s}$ and $\mathrm{n} \geq 2$ be a positive integer:

(i) If $\mathrm{s}=2$, then

$$
\Pi_{\mathrm{q} ; \mathrm{q}}^{\mathrm{n}}\left(\mathrm{X}_{1}, \ldots, \mathrm{X}_{\mathrm{n}} ; \mathrm{Y}\right) \subseteq \Pi_{\mathrm{p} ; \mathrm{p}}^{\mathrm{n}}\left(\mathrm{X}_{1}, \ldots, \mathrm{X}_{\mathrm{n}} ; \mathrm{Y}\right)
$$

holds true for $1 \leq \mathrm{p} \leq \mathrm{q} \leq 2$.

(ii) If $\mathrm{s}>2$, then

$$
\Pi_{\mathrm{q} ; \mathrm{q}}^{\mathrm{n}}\left(\mathrm{X}_{1}, \ldots, \mathrm{X}_{\mathrm{n}} ; \mathrm{Y}\right) \subseteq \Pi_{\mathrm{p} ; \mathrm{p}}^{\mathrm{n}}\left(\mathrm{X}_{1}, \ldots, \mathrm{X}_{\mathrm{n}} ; \mathrm{Y}\right)
$$

holds true for $1 \leq \mathrm{p} \leq \mathrm{q}<\mathrm{s}^{*}<2$.

As a consequence of results from [3] one can easily prove the following generalization of this result (see [2] for details):

Theorem 1.2. If $\mathrm{X}_{1}$ has cotype 2 and $1 \leq \mathrm{p} \leq \mathrm{s} \leq 2$, then

$$
\Pi_{s ; s, q, \ldots, q}^{n}\left(X_{1}, \ldots, X_{n} ; Y\right) \subseteq \Pi_{p ; p, q, \ldots, q}^{n}\left(X_{1}, \ldots, X_{n} ; Y\right)
$$


for all $\mathrm{X}_{2}, \ldots, \mathrm{X}_{\mathrm{n}}, \mathrm{Y}$ and all $\mathrm{q} \geq 1$. In particular

$$
\Pi_{s ; s}^{n}\left(X_{1}, \ldots, X_{n} ; Y\right) \subseteq \Pi_{p ; p, s, \ldots, s}^{n}\left(X_{1}, \ldots, X_{n} ; Y\right) \subseteq \Pi_{p ; p}^{n}\left(X_{1}, \ldots, X_{n} ; Y\right) .
$$

A similar result, mutatis mutandis, holds if $\mathrm{X}_{\mathbf{j}}$ (instead of $\mathrm{X}_{1}$ ) has cotype 2.

In this note we remark that analogous results hold for other situations in which the spaces involved may have different cotypes and no space may have necessarily cotype 2 .

\section{Results}

The following proposition can be found in [5]:

Proposition 2.1. Let $1 \leq p_{1}, \ldots, p_{n}, p, q_{1}, \ldots, q_{n}, q \leq \infty$ such that $1 / t \leq \sum_{j=1}^{n} 1 / t_{j}$ for $\mathrm{t} \in\{p, q\}$. Let $0<\theta<1$ and define

$$
\frac{1}{r}=\frac{1-\theta}{p}+\frac{\theta}{q} \text { and } \frac{1}{r_{j}}=\frac{1-\theta}{p_{j}}+\frac{\theta}{q_{j}} \text { for all } j=1, \ldots, n
$$

and let $\mathrm{T} \in \mathcal{L}\left(\mathrm{X}_{1}, \ldots, \mathrm{X}_{\mathrm{n}} ; \mathrm{Y}\right)$. Then

$$
\mathrm{T} \in \Pi_{\mathfrak{p} ; \mathfrak{p}_{1}, \ldots, \mathfrak{p}_{\mathfrak{n}}}^{\mathrm{n}} \cap \Pi_{\mathbf{q}_{\mathbf{q}} \mathrm{q}_{1}, \ldots, \mathrm{q}_{\mathrm{n}}}^{\mathrm{n}} \text { implies } \mathrm{T} \in \Pi_{\mathrm{r} ; \mathrm{r}_{1}, \ldots, \mathrm{r}_{\mathrm{n}}}^{\mathrm{n}},
$$

provided that for each $\mathrm{j}=1, \ldots, \mathrm{n}$, one of the following conditions holds:

(i) $\mathrm{X}_{\mathrm{j}}$ is an $\mathcal{L}_{\infty}$-space;

(ii) $X_{j}$ is of cotype 2 and $1 \leq p_{j}, q_{j} \leq 2$;

(iii) $X_{j}$ is of finite cotype $s_{j}>2$ and $1 \leq p_{j}, q_{j}<s_{j}^{*}$;

(iv) $\mathrm{p}_{j}=\mathrm{q}_{j}=\mathrm{r}_{\mathrm{j}}$.

Next lemma appears in [13, Theorem 3.1] without proof. We present a proof for the sake of completeness:

Lemma 2.2. Let $\mathrm{s}>0$. Suppose that $\mathrm{X}_{\mathrm{j}}$ has cotype $\mathrm{s}_{\mathrm{j}}$ for all $\mathrm{j}=1, \ldots, \mathrm{n}$ and at least one of the $\mathrm{s}_{\mathrm{j}}$ is finite. If

$$
\frac{1}{s} \leq \frac{1}{s_{1}}+\ldots+\frac{1}{s_{n}}
$$

then

$$
\mathcal{L}\left(X_{1}, \ldots, X_{n} ; Y\right)=\Pi_{s ; b_{1}, \ldots, b_{n}}^{n}\left(X_{1}, \ldots, X_{n} ; Y\right)
$$

for

$$
\mathrm{b}_{j}=1 \text { if } \mathrm{s}_{j}<\infty \text { and } \mathrm{b}_{j}=\infty \text { if } \mathrm{s}_{j}=\infty \text {. }
$$


Proof. Let $j_{1}, \ldots, j_{k} \in\{1, \ldots, n\}, k \leq n$ such that $s_{j_{1}}, \ldots, s_{j_{k}}$ are finite and $s_{j}=\infty$ if $j \neq j_{1}, \ldots, j_{k}$.

If $\left(x_{i}^{\left(j_{l}\right)}\right)_{i=1}^{\infty} \in \ell_{1}^{w}\left(X_{j_{l}}\right)$ and $\left(x_{i}^{(j)}\right)_{i=1}^{\infty} \in \ell_{\infty}\left(X_{j}\right), j \neq j_{l}, l=1, \ldots, k$, using Generalized Hölder Inequality, we obtain

$$
\begin{aligned}
\left(\sum_{i=1}^{\infty}\left\|\mathrm{T}\left(x_{i}^{(1)}, \ldots, x_{i}^{(n)}\right)\right\|^{s}\right)^{\frac{1}{s}} & \leq\|\mathrm{T}\|\left(\sum_{i=1}^{\infty}\left(\left\|x_{i}^{(1)}\right\| \cdots\left\|x_{i}^{(n)}\right\|\right)^{s}\right)^{\frac{1}{s}} \\
& \leq \mathrm{C}\|\mathrm{T}\|\left(\sum_{i=1}^{\infty}\left\|x_{i}^{\left(j_{1}\right)}\right\|^{s_{j_{1}}}\right)^{1 / s_{j_{1}}} \cdots\left(\sum_{i=1}^{\infty}\left(\left\|x_{i}^{\left(j_{k}\right)}\right\|\right)^{s_{j_{k}}}\right)^{1 / s_{j_{k}}}
\end{aligned}
$$

where $C$ is such that

$$
\prod_{j=1, j \neq j_{1}, \ldots, j_{n}}^{n}\left\|x_{i}^{(j)}\right\| \leq C
$$

for all $i$. Since $X_{j}$ has cotype $s_{j}$, for $j_{1}, \ldots, j_{k}$, we have

$$
\begin{aligned}
\left(\sum_{i=1}^{\infty}\left\|\mathrm{T}\left(x_{i}^{(1)}, \ldots, x_{i}^{(n)}\right)\right\|^{s}\right)^{\frac{1}{s}} & \leq \mathrm{C}\|\mathrm{T}\|\left(\sum_{i=1}^{\infty}\left\|x_{i}^{\left(j_{1}\right)}\right\|^{s_{j_{1}}}\right)^{1 / s_{j_{1}}} \cdots\left(\sum_{i=1}^{\infty}\left(\left\|x_{i}^{\left(j_{k}\right)}\right\|\right)^{s_{j_{k}}}\right)^{1 / s_{j_{k}}} \\
& =\mathrm{C}\|\mathrm{T}\| \prod_{t=1}^{k}\left(\sum_{i=1}^{\infty}\left\|i d_{x_{j_{t}}}\left(x_{i}^{\left(j_{t}\right)}\right)\right\|^{s_{j_{t}}}\right)^{1 / s_{j_{t}}}<\infty
\end{aligned}
$$

and the result follows.

The main result of this note is the following Theorem. At first glance it seems to have too restrictive assumptions, but Corollary 2.4 and Example 2.5 will illustrate its usefulness:

Theorem 2.3. Let $\mathrm{k}, \mathrm{n}$ be natural numbers, $\mathrm{n} \geq \mathrm{k} \geq 2$ and $\mathrm{X}_{\mathrm{k}+1}, \ldots, \mathrm{X}_{\mathrm{n}}, \mathrm{Y}$ be arbitrary Banach spaces. If $\mathrm{X}_{\mathbf{j}}$ has finite cotype $\mathrm{s}_{\mathrm{j}} \geq 2$ for $\mathrm{j}=1, \ldots, \mathrm{k}$, then

$$
\Pi_{p ; p_{1}, \ldots, p_{k}, q, \ldots, q}^{n}\left(X_{1}, \ldots, X_{n} ; Y\right) \subseteq \Pi_{r ; r_{1}, \ldots, r_{k}, q, \ldots, q}^{n}\left(X_{1}, \ldots, X_{n} ; Y\right)
$$

for any $(\mathbf{q}, \theta) \in[1, \infty] \times(0,1)$,

$$
\begin{aligned}
& 1 \leq p_{j} \leq 2\left(\text { when } s_{j}=2\right) \\
& 1 \leq p_{j}<s_{j}^{*}\left(\text { when } s_{j}>2\right)
\end{aligned}
$$

and $\mathrm{s} \in[1, \infty)$ so that

$$
\begin{aligned}
& \frac{1}{s} \leq \frac{1}{s_{1}}+\cdots+\frac{1}{s_{k}}, \\
& \frac{1}{r}=\frac{1-\theta}{s}+\frac{\theta}{p} \\
& \frac{1}{r_{j}}=\frac{1-\theta}{1}+\frac{\theta}{p_{j}},
\end{aligned}
$$

for all $\mathbf{j}=1, \ldots, k$. 
Proof. Let $T \in \Pi_{\mathfrak{p} ; p_{1}, \ldots, p_{k}, \mathfrak{q}, \ldots, q}^{\mathfrak{q}}\left(X_{1}, \ldots, X_{n} ; Y\right)$. By the previous lemma,

$$
\mathcal{L}\left(X_{1}, \ldots, X_{n} ; Y\right)=\Pi_{s ; 1, \ldots, 1, \infty, \ldots, \infty}^{n}\left(X_{1}, \ldots, X_{n} ; Y\right)
$$

where 1 is repeated $k$ times. A fortiori, we have

$$
\mathcal{L}\left(X_{1}, \ldots, X_{n} ; Y\right)=\Pi_{s ; 1, \ldots, 1, q, \ldots, q}^{n}\left(X_{1}, \ldots, X_{n} ; Y\right) .
$$

So,

$$
T \in \Pi_{s ; 1, \ldots, 1, q, \ldots, q}^{n}\left(X_{1}, \ldots, X_{n} ; Y\right) \cap \Pi_{p ; p_{1}, \ldots, p_{k}, q, \ldots, q}^{n}\left(X_{1}, \ldots, X_{n} ; Y\right) .
$$

From Proposition 2.1 we get

$$
\mathrm{T} \in \Pi_{\mathrm{r} ; \mathrm{r}_{1}, \ldots, \mathrm{r}_{k}, \mathrm{q}, \ldots, \mathrm{q}}^{\mathrm{n}}\left(\mathrm{X}_{1}, \ldots, \mathrm{X}_{\mathrm{n}} ; \mathrm{Y}\right) .
$$

Corollary 2.4. Let $\mathrm{k}, \mathrm{n}$ be natural numbers, $\mathrm{n} \geq \mathrm{k} \geq 2, \mathrm{X}_{\mathrm{k}+1}, \ldots, \mathrm{X}_{\mathrm{n}}, \mathrm{Y}$ be arbitrary Banach spaces and $\mathrm{q} \in[1, \infty)$. If $\mathrm{X}_{\mathrm{j}}$ has finite cotype $\mathrm{s}_{\mathrm{j}} \geq 2, j=1, \ldots, \mathrm{k}$ and $1 \leq 1 / \mathrm{s}_{1}+\cdots+1 / \mathrm{s}_{\mathrm{k}}$, then

$$
\Pi_{\mathbf{p} ; p_{1}, \ldots, p_{k}, q, \ldots, q}^{n}\left(X_{1}, \ldots, X_{n} ; Y\right) \subseteq \Pi_{r ; r_{1}, \ldots, r_{k}, q, \ldots, q}^{n}\left(X_{1}, \ldots, X_{n} ; Y\right),
$$

where $\mathrm{p}_{\mathrm{j}}=\mathrm{p}$ and $\mathrm{r}_{\mathrm{j}}=\mathrm{r}$ for all $\mathrm{j}=1, \ldots, \mathrm{k}$, for all $\mathrm{r}$ so that

$$
\begin{aligned}
& 1 \leq r<p<\text { min } s_{j}^{*} \text { if } s_{j} \neq 2 \text { for some } j=1, \ldots, k, \\
& 1 \leq r<p \leq 2 \text { if } s_{j}=2 \text { for all } j=1, \ldots, k .
\end{aligned}
$$

In particular

$$
\Pi_{p ; p}^{n}\left(X_{1}, \ldots, X_{n} ; Y\right) \subseteq \Pi_{r ; r}^{n}\left(X_{1}, \ldots, X_{n} ; Y\right)
$$

for all $\mathrm{r}$ so that

$$
\begin{aligned}
& 1 \leq r<p<\min s_{j}^{*} \text { if } s_{j} \neq 2 \text { for some } j=1, \ldots, k \\
& 1 \leq r<p \leq 2 \text { if } s_{j}=2 \text { for all } j=1, \ldots, k .
\end{aligned}
$$

Proof. Since $1 \leq 1 / s_{1}+\cdots+1 / s_{k}$, we can use $s=1$ in the previous theorem. Since $p=p_{i}$ and $r=r_{i}$ for all $i=1, \ldots, k$ and $s=1$, we conclude that

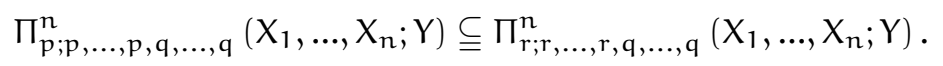

In fact, for any $1 \leq r<p$ there is a $\theta \in(0,1)$ so that

$$
\frac{1}{r}=\frac{1-\theta}{1}+\frac{\theta}{p}
$$

and since $p=p_{i}$ and $r=r_{i}$, the same $\theta \in(0,1)$ satisfies

$$
\frac{1}{r_{i}}=\frac{1-\theta}{1}+\frac{\theta}{p_{i}} \text {. }
$$


Choosing $q=p$, since $r<p$ we have

$$
\Pi_{p ; p}^{n}\left(X_{1}, \ldots, X_{n} ; Y\right) \subseteq \Pi_{r ; r, \ldots, r, p, \ldots, p}^{n}\left(X_{1}, \ldots, X_{n} ; Y\right) \subseteq \Pi_{r ; r}^{n}\left(X_{1}, \ldots, X_{n} ; Y\right) .
$$

Example 2.5. Let $\mathrm{X}_{4}, \ldots, \mathrm{X}_{\mathrm{n}}, \mathrm{Y}$ be arbitrary Banach spaces. Then

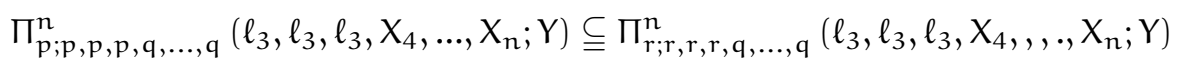

for all $\mathrm{q} \in[1, \infty)$ and $1 \leq \mathrm{r}<\mathrm{p}<3^{*}$. In particular

$$
\Pi_{p ; p}^{\mathrm{n}}\left(\ell_{3}, \ell_{3}, \ell_{3}, X_{4}, \ldots, X_{n} ; Y\right) \subseteq \Pi_{r ; r}^{n}\left(\ell_{3}, \ell_{3}, \ell_{3}, X_{4},,, ., X_{n} ; Y\right)
$$

for all $1 \leq \mathrm{r}<\mathrm{p}<3^{*}$.

\section{Received: January 2011. Revised: February 2011.}

\section{References}

[1] R. Alencar and M. C. Matos, Some classes of multilinear mappings between Banach spaces, Publicaciones del Departamento de Análisis Matemático 12, Universidad Complutense Madrid, (1989).

[2] A. Thiago Bernardino and D. Pellegrino, Some remarks on absolutely summing multilinear operators, arXiv:1101.2119v2.

[3] O. Blasco, G. Botelho, D. Pellegrino and P. Rueda, Lifting summability properties for multilinear mappings, preprint.

[4] G. Botelho, Cotype and absolutely summing multilinear mappings and homogeneous polynomials, Proc. Roy. Irish Acad Sect. A 97 (1997), 145-153.

[5] G. Botelho, C. Michels and D. Pellegrino, Complex interpolation and summability properties of multilinear operators, Rev. Matem. Complut. 23 (2010), 139-161.

[6] G. Botelho, D. Pellegrino and P. Rueda, Cotype and absolutely summing linear operators, Mathematische Zeitschrift, 267 (2011), 1-7.

[7] E. Çalı̧̧kan and D. M. Pellegrino, On the multilinear generalizations of the concept of absolutely summing operators, Rocky Mount. J. Math. 37 (2007), 1137-1154.

[8] A. Defant, D. Popa and U. Schwarting, Coordenatewise multiple summing operators on Banach spaces, J. Funct. Anal. 259 (2010), 220-242. 
[9] J. Diestel, H. Jarchow and A. Tonge, Absolutely summing operators, Cambridge University Press, 1995.

[10] H. Junek, M.C. Matos and D. Pellegrino, Inclusion theorems for absolutely summing holomorphic mappings, Proc. Amer. Math. Soc. 136 (2008), 3983-3991.

[11] Y. Meléndez and A. Tonge, Polynomials and the Pietsch Domination Theorem, Proc. Roy. Irish Acad Sect. A 99 (1999), 195-212.

[12] D. Pellegrino, Cotype and absolutely summing homogeneous polynomials in $\mathrm{L}_{p}$ spaces, Studia Math. 157 (2003), 121-131.

[13] D. Pellegrino, Cotype and nonlinear absolutely summing mappings, Math. Proc. Roy. Irish Acad., 105A (2005), 75-91.

[14] D. Pellegrino and J. Santos, Absolutely summing operators: a panorama, Quaestiones Mathematicae 34 (2011), 447-478.

[15] D. Popa, Reverse inclusions for multiple summing operators, J. Math. Anal. Appl. 350 (2009), 360-368.

[16] D. Popa, Multilinear variants of Maurey and Pietsch theorems and applications, J. Math. Anal. Appl. 368 (2010) 157-168. 